\title{
Long-term psychological outcome of 1999 Taiwan earthquake survivors: a survey of a high-risk sample with property damage
}

\author{
Chin-Hung Chen ${ }^{\mathrm{a}}$, Happy Kuy-Lok Tan ${ }^{\mathrm{b}}$, Long-Ren Liao ${ }^{\mathrm{c}}$, Hsiu-Hsi Chen ${ }^{\mathrm{d}}$, \\ Chang-Chuan Chan ${ }^{\mathrm{e}}$, Joseph-Jror-Serk Cheng ${ }^{\mathrm{f}}$, Chung-Ying Chen ${ }^{\mathrm{a}}$, \\ Tsu-Nai Wang ${ }^{\mathrm{g}}$, Mong-Liang $\mathrm{Lu}^{\mathrm{h}}$,* \\ ${ }^{a}$ Department of Psychiatry, Tsao-Tun Psychiatric Center, Nantou, Taiwan \\ ${ }^{\mathrm{b}}$ Taoyuan Mental Hospital, Taoyuan County, Taiwan \\ ${ }^{\mathrm{c}}$ Health Bureau, Nantou County Government, Nantou, Taiwan \\ ${ }^{\mathrm{d}}$ Institute of Preventive Medicine, College of Public Health, National Taiwan University, Taipei, Taiwan \\ ${ }^{\mathrm{e}}$ Institute of Occupational Medicine and Industrial Hygiene, College of Public Health, National Taiwan University, Taipei, Taiwan \\ f Bali Mental Hospital, Taipei County, Taiwan \\ ${ }^{\mathrm{g}}$ School of Public Health, Kaohsiung Medical University, Kaohsiung, Taiwan \\ ${ }^{\mathrm{h}}$ Department of Psychiatry, Taipei Medical University-Wan Fang Hospital, Taipei 116, Taiwan
}

\begin{abstract}
Objective: Severe natural disasters can cause long-term psychological impact on the survivors. This study aimed to examine the prevalence and risk factors of posttraumatic stress symptoms and psychiatric morbidity among survivors of the severe earthquake that occurred in ChiChi, Taiwan, in September 21, 1999.

Methods: A total of 6412 earthquake survivors whose houses were destroyed by earthquake were recruited about 2 years after the disaster. They completed a self-report questionnaire assessing posttraumatic stress symptoms, psychiatric morbidity, and information of demographics, trauma exposure, and current living status.

Results: The estimated rates of posttraumatic stress disorder caseness and psychiatric morbidity were $20.9 \%$ and $39.8 \%$, respectively. Psychiatric morbidity occurred mainly in survivors who were female, older, with low education level, and currently living in a prefabricated house. The risk factors for posttraumatic stress disorder caseness were female sex, currently living in a prefabricated house, low education level, and experienced complete destruction of property.

Conclusion: These results showed that severe earthquake can cause long-term psychological impact in the survivors. The findings of risk factors suggest avenues for targeting postdisaster interventions.

(C) 2007 Elsevier Inc. All rights reserved.
\end{abstract}

\section{Introduction}

Earthquakes have been responsible for many of the most devastating natural disasters of the 20th century. Unlike other natural disasters, an earthquake usually occurs without warning, the impact is widespread and severe, and the effects often persist long afterward. In the aftermath of the earthquake, the threat of injury may continue for weeks, with the possibility of aftershocks. Disruptions may be experienced for several years as survivors are relocated and towns are rebuilt.

\footnotetext{
* Corresponding author. Tel.: +886 2 29307930; fax: +886 2 29334920

E-mail address: mongliang@hotmail.com (M.-L. Lu).
}

In the short term, disasters have been found to be associated with increased prevalence of psychiatric morbidity, for example, posttraumatic stress disorder (PTSD), depression, anxiety, sleep disorder, and substance abuse [1-4]. Posttraumatic stress disorder has been found to be the most prevalent type of psychiatric morbidity after disaster $[2,5]$. The reported PTSD rates after natural disasters varied widely, ranging from $1.5 \%$ in a population affected by Hurricane Andrew [6] to $74 \%$ in Armenian earthquake victims [7]. The rates of major depression in disaster survivors range from $13 \%$ to $52 \%[7,8]$, whereas the prevalence of minor psychiatric morbidity among disaster victims varies from $25 \%$ [9] to $89.9 \%$ [10]. Such variability in the reported rates of postdisaster psychiatric morbidity may be due to differences in methodology, the severity of 
disaster, the time elapsed between the onset of the disaster and data collection, the methods of sampling and case detection, and the diagnostic criteria. Findings concerning risk factors of postdisaster psychological problems are also varied. Postearthquake psychological distress related to greater exposure to actual or threatened injury during the earthquake, closeness to the epicenter, disruption in life and social network, preexisting history of emotional problems, financial loss, female sex, low educational level, and lack of support [11-14].

For most individuals, the meaning attributed to a traumatic event is the product of a complex interaction based on the event itself, personal history, and future expectation, as well as biological factors, which combine to produce the stress effect as a whole [15]. The long-term sequelae of disasters have been studied less extensively. However, reports suggest that the psychological consequences of earthquake exposure are long lasting and may be related to the damage/loss in the earthquake [16]. After the 1989 Newcastle earthquake, $48 \%$ of the survivors who had PTSD at 6 months after still had PTSD at the 2-year postearthquake assessment [17]. The study showed that psychological morbidity declined over time but tended to stabilize at about 12 months postdisaster for general morbidity and at about 18 months for trauma-related morbidity [17].
On 21 September 1999, an earthquake with a magnitude of 7.3 on the Richter scale struck Taiwan. The Chi-Chi earthquake caused more than 2300 deaths, injured more than 8000 people, and damaged or destroyed more than 100000 homes. It was the most devastating disaster that had occurred in Taiwan in the last hundred years. Many survivors had stress-related disorder and PTSD. Recent study showed that the rates of PTSD, major depression, and minor psychiatric morbidity in the early stage after the Chi-Chi earthquake were $37 \%, 16 \%$, and $89.9 \%$, respectively $[10,18]$. Another study that surveyed the psychiatric disorder among the Chi-Chi earthquake survivors within 6 months of the disaster reported that the prevalence rates of PTSD and major depression were $7.9 \%$ and $9.5 \%$, respectively [19]. The study by Lai et al [20] reported that the prevalence rates of full and partial PTSD among the Chi-Chi earthquake survivors were $10.3 \%$ and $19.0 \%$, respectively. The risk factors of PTSD included female sex, lower educational level, and greater trauma exposure [20]. Our Medline search found several articles related to the prevalence and risk factors of psychiatric problems after the Chi-Chi earthquake. They varied in the inclusion criteria of the study subjects, the time elapsed between the onset of the disaster and data collection, the methods of sampling and case detection, and the diagnostic criteria.

Table 1

Summary of reported studies of psychiatric impact of the Chi-Chi earthquake

\begin{tabular}{|c|c|c|c|c|c|}
\hline Study & $\begin{array}{l}\text { Study period } \\
\text { after earthquake }\end{array}$ & Subjects & Method & Prevalence & Risk factors \\
\hline $\begin{array}{l}\text { Chen } \\
\text { et al [10] }\end{array}$ & $1 \mathrm{mo}$ & 525 residents & CHQ-12 & $\begin{array}{l}\text { Psychiatric } \\
\text { morbidity: } \\
89.9 \%\end{array}$ & $\begin{array}{l}\text { Female, serious destruction of property, and } \\
\text { personality characteristics of nervousness and } \\
\text { obsessiveness }\end{array}$ \\
\hline $\begin{array}{l}\text { Hsu } \\
\quad \text { et al [21] }\end{array}$ & $6 \mathrm{wk}$ & $\begin{array}{l}323 \\
\text { adolescents }\end{array}$ & $\begin{array}{l}\text { Children's Interview } \\
\text { for Psychiatric } \\
\text { Syndromes }\end{array}$ & PTSD: $21.7 \%$ & $\begin{array}{l}\text { Being physically injured and experiencing the } \\
\text { death of a close family member }\end{array}$ \\
\hline $\begin{array}{l}\text { Kuo } \\
\quad \text { et al }[18]\end{array}$ & $2 \mathrm{mo}$ & $\begin{array}{l}120 \text { bereaved } \\
\text { survivors }\end{array}$ & MINI & $\begin{array}{l}\text { PTSD: } 37 \% \\
\text { MDD: } 16 \%\end{array}$ & $\begin{array}{l}\text { PTSD: psychosocial stressors, initial feelings of } \\
\text { guilt } \\
\text { MDD: female }\end{array}$ \\
\hline $\begin{array}{l}\text { Yang } \\
\text { et al [22] }\end{array}$ & $3-4 \mathrm{mo}$ & 663 victims & $\begin{array}{l}\text { CHQ-12 } \\
\text { The posttraumatic } \\
\text { symptoms checklist }\end{array}$ & $\begin{array}{l}\text { Psychiatric } \\
\text { morbidity: } 24.5 \% \\
\text { PTSD: } 11.3 \% \\
\text { Partial PTSD: } 32.0 \%\end{array}$ & $\begin{array}{l}\text { Psychiatric morbidity: financial strain, nervous } \\
\text { trait, female, elderly } \\
\text { PTSD: nervous trait, elderly, the degree of } \\
\text { destruction of house, female }\end{array}$ \\
\hline $\begin{array}{l}\text { Chang } \\
\text { et al [23] }\end{array}$ & $5 \mathrm{mo}$ & $\begin{array}{l}84 \text { male } \\
\text { firefighters }\end{array}$ & $\begin{array}{l}\text { CHQ-12 } \\
\text { IES }\end{array}$ & $\begin{array}{l}\text { Psychiatric } \\
\text { morbidity: } 16.7 \% \\
\text { Posttraumatic } \\
\text { morbidity: } \\
21.4 \%\end{array}$ & $\begin{array}{l}\text { Psychiatric morbidity: job experience, confron- } \\
\text { tive coping } \\
\text { Posttraumatic morbidity: job experience, distanc- } \\
\text { ing, escape avoidance, and positive reappraisal }\end{array}$ \\
\hline $\begin{array}{l}\text { Chou } \\
\text { et al [19] }\end{array}$ & $6 \mathrm{mo}$ & 442 residents & MINI & $\begin{array}{l}\text { MDD: } 9.5 \% \\
\text { PTSD: } 7.9 \%\end{array}$ & $\begin{array}{l}\text { MDD: divorced/widowed status, lower education } \\
\text { level, prominent house damage } \\
\text { PTSD: female, having sought medical service } \\
\text { after the earthquake }\end{array}$ \\
\hline $\begin{array}{l}\text { Lai } \\
\text { et al [20] } \\
\text { and Chang } \\
\text { et al [24] }\end{array}$ & $10 \mathrm{mo}$ & 252 subjects & $\begin{array}{l}\text { CHQ-12 } \\
\text { MINI }\end{array}$ & $\begin{array}{l}\text { Psychiatric } \\
\text { morbidity: } 38.1 \% \\
\text { PTSD: } 10.3 \% \\
\text { Partial PTSD: } 19.0 \%\end{array}$ & $\begin{array}{l}\text { PTSD: female, lower educational level, current } \\
\text { depression, greater trauma exposure, previous } \\
\text { traumatic experiences, impaired well-being }\end{array}$ \\
\hline Wu et al [25] & $3 y$ & 405 subjects & $\begin{array}{l}\text { MINI } \\
\text { Medical Outcomes } \\
\text { Study Short } \\
\text { Form-36 }\end{array}$ & $\begin{array}{l}\text { MDD: } 6.4 \% \\
\text { PTSD: } 4.4 \%\end{array}$ & $\begin{array}{l}\text { Poor QOL: age, female, economic problems, } \\
\text { physical illness, subjective memory and social- } \\
\text { activity decline, diagnosis of PTSD or MDD }\end{array}$ \\
\hline
\end{tabular}

MDD indicates major depressive disorder; MINI, Mini International Neuropsychiatric Interview; QOL, quality of life; IES, Impact of Event Scale. 
The characteristics of each of these studies are summarized in Table 1.

This article is intended to report the frequency of psychiatric morbidity and posttraumatic stress symptoms among those who had property loss and/or resettlement stress during the 2-year period after the Chi-Chi earthquake. Associations between risk factors and the occurrence of psychiatric morbidity and posttraumatic symptoms are also presented.

\section{Methods}

\subsection{Subjects}

Nantou County is located in the middle of Taiwan and has a population of 540000 . It was the epicenter of the Chi-Chi earthquake. In the whole county, 927 people were killed and 60000 houses were destroyed by the earthquake. The Health Bureau of Nantou County conducted the integrated screening program for rebuilding community health, which aimed at screening the health conditions of people whose houses were destroyed by the earthquake. A cross-sectional health survey was conducted among individuals living in Nantou County 2 years after the Chi-Chi earthquake. The survey consisted of demographic data, medical and psychological assessment, and hematologic and biochemistry tests. The sample of this study consisted of 8998 earthquake survivors whose houses were completely or partially destroyed by the earthquake. They were immediately relocated to prefabricated houses after the disaster. The population remaining in prefabricated houses decreased week by week, but people without alternative housing remained there. The public heath nurses visited the victims according to the government registration database and interviewed the evacuees. Some subjects worked during the day, refused to participate, or were unable to be located, and therefore were unavailable for interview. Of the 8998 survivors, 2586 subjects could not be reached during the screening period. The remaining 6412 subjects were available for analysis. The present report involves part of the psychological data gathered by this program.

\subsection{Assessment instruments}

The study was approved and supported by the Health Bureau of Nantou County and the Department of Health, Taiwan. The screening procedure was conducted by public health nurses who underwent a training program to become familiarized with the assessment instruments. The purpose of the screening was explained to the survivors, and written consent was obtained from all of the respondents. For illiterate subjects, the interviewee would read the scale and record according to their response. The assessment questionnaire consisted of 3 parts. The first part included information about basic demography, destruction of property, and current housing status. The second part was the 12-item Chinese Health Questionnaire (CHQ-12) [26]. The third part was the Chinese version of SPAN (SPAN-C) [27].

Destruction of property was classified into 4 categories: completely destroyed, partially destroyed, mildly damaged, and not damaged at all. The extent of damage was determined by the staff from the government agency for construction engineering. In our study, all of the subjects' houses were completely or partially destroyed by the ChiChi earthquake. Some of them who could not find residence were arranged to live in prefabricated houses after earthquake.

The CHQ-12, which is a standardized screening instrument for nonpsychotic morbidity, has been tested and applied in surveys of minor psychiatric morbidity in community [28] and clinical settings [29]. It is derived from the 30-item General Health Questionnaire [30], with the addition of specially designed, culturally relevant items. It inquires about anxiety, depression, poor family relationships, somatic symptoms, and sleep problems. The 12-items on the CHQ-12 are each rated on a 4-point scale and scored on the basis of 0-0-1-1. It can be used to identify a "probable clinical case" on the basis of a cutoff score and determine the severity of morbidity on the basis of the total score ranging from 0 to 12 . The higher the score, the more severe is the psychiatric morbidity. The sensitivity and specificity in the prediction of psychiatric morbidity were $69.6 \%$ and $94.8 \%$, respectively, in the community study (cutoff 2/3) [28] and $78 \%$ and $77 \%$, respectively, in general health clinics (cutoff 3/4) [29]. In this study, a probable case of psychiatric morbidity was defined using a cutoff $2 / 3$ for comparison with results of the previous community study.

The Davidson Trauma Scale (DTS) is a validated 17item self-rating scale for PTSD [31,32]. The DTS measures each Diagnostic and Statistical Manual of Mental Disorders-IV symptom of PTSD on 5-point frequency and severity scales. The SPAN (named for its principal 4 items: startle, physiological arousal, anger, and numbness) was developed to serve as a shorter version of DTS [33]. The SPAN, which correlated significantly with the Impact of Events Scale, the Sheehan Disability Scale, and the Structured Interview of PTSD, was found to have a diagnostic accuracy of $88 \%$. The Chinese version of SPAN (SPAN-C) has been validated in the study of the Chi-Chi earthquake survivors [27]. The SPAN-C showed good internal consistency (Cronbach $\alpha=.77$ ) and test-retest reliability $(r=0.90)$. Concurrent validity was obtained against the clinical diagnostic interview, with a diagnostic accuracy of 0.8 at a SPAN-C score of 5 [27].

\subsection{Data analysis}

Simple descriptive statistics such as means, standard deviations, and proportions were used when appropriate. Student $t$ test, 1-way analysis of variance, and $\chi^{2}$ tests were used to analyze group differences. A multiple logistic 
Table 2

Risk factors and psychiatric morbidity

\begin{tabular}{|c|c|c|c|}
\hline & CHQ-12 $\geq 3$ & CHQ-12 <3 & $P$ \\
\hline \multicolumn{4}{|l|}{ Sex } \\
\hline Male & $817(33.2 \%)$ & $1614(42.5 \%)$ & \multirow[t]{2}{*}{$<.000$} \\
\hline Female & $1642(66.8 \%)$ & $2182(57.5 \%)$ & \\
\hline \multicolumn{4}{|l|}{ Age group (y) } \\
\hline$<40$ & $495(20.1 \%)$ & $737(19.4 \%)$ & \multirow[t]{3}{*}{.002} \\
\hline $40-65$ & $1295(52.7 \%)$ & $1866(49.2 \%)$ & \\
\hline$>65$ & $669(27.2 \%)$ & $1193(31.4 \%)$ & \\
\hline \multicolumn{4}{|l|}{ Marital status } \\
\hline Single & $158(6.4 \%)$ & $283(7.5 \%)$ & \multirow[t]{3}{*}{.017} \\
\hline Married & $1845(75.0 \%)$ & $2904(76.5 \%)$ & \\
\hline Divorced/widowed & $456(18.5 \%)$ & $609(16.0 \%)$ & \\
\hline \multicolumn{4}{|l|}{ Education level } \\
\hline Primary school & $1611(65.5 \%)$ & $2374(62.5 \%)$ & \multirow[t]{3}{*}{.001} \\
\hline High school & $685(27.9 \%)$ & $1073(28.3 \%)$ & \\
\hline College and above & $163(6.6 \%)$ & $349(9.2 \%)$ & \\
\hline \multicolumn{4}{|l|}{ Destruction of property } \\
\hline Completely destroyed & $1337(54.4 \%)$ & $2007(52.9 \%)$ & \multirow[t]{2}{*}{.254} \\
\hline Partially destroyed & $1122(45.6 \%)$ & $1789(47.1 \%)$ & \\
\hline \multicolumn{4}{|l|}{ Current living environment } \\
\hline Prefabricated house & $394(16.0 \%)$ & $490(12.9 \%)$ & \multirow[t]{2}{*}{$<.000$} \\
\hline Not prefabricated house & $2065(84.0 \%)$ & $3306(87.1 \%)$ & \\
\hline
\end{tabular}

Values are presented as number (percentage).

regression model was used to identify significant variables affecting psychiatric morbidity and PTSD caseness by SPAN-C. Differences were considered significant if the $P$ value was smaller than .05 .

\section{Results}

\subsection{Demographic characteristics}

A total of 6412 earthquake survivors were included into this study. The mean age was $54.2 \pm 15.0$ years; $61.2 \%$ (3924 of 6412) were female and $38.8 \%$ male. Of the survivors, $53.4 \%$ (3427 of 6412) reported that their houses were completely destroyed by the earthquake and $46.6 \%$ partially destroyed. Two years after the Chi-Chi earthquake, $14.2 \%$ (909 of 6412) still lived in prefabricated houses.

\subsection{Psychiatric morbidity}

If an item on the CHQ-12 was rated as 1, we would define that particular symptom as present. Of the psychiatric symptoms measured with the CHQ-12, the most frequently encountered symptom was insomnia (31.0\%). One third of subjects experienced dizziness and headache (30.1\%), palpitation (30.1\%), and psychological distress $(30.0 \%)$. One fourth of subjects reported chest tightness (29.2\%), tremor $(28.4 \%)$, and nervousness $(24.0 \%)$. One fifth of subjects had worry about family and friend (21.8\%) and no confidence about the future (15.6\%). Lack of confidence, feelings of hopeless, and relationship problem with family occurred in $13.3 \%, 11.7 \%$, and $8.3 \%$, respectively. The mean CHQ-12 score was $2.73 \pm 3.2$. The prevalence of probable psychiatric morbidity based on CHQ-12 score of 3 or above was $39.8 \%$.
Factors significantly associated with the psychiatric morbidity were analyzed. The results showed that female sex $\left(\chi^{2}=54.2, d f=1, P<.001\right)$, divorced/widowed status $\left(\chi^{2}=8.2, d f=2, P=.017\right)$, middle-aged subjects (40-65 years old $)\left(\chi^{2}=13.0, d f=2, P=.002\right)$, low education level $\left(\chi^{2}=14.2, d f=2, P=.001\right)$, and living in prefabricated house $\left(\chi^{2}=11.9, d f=1, P<.001\right)$ were related to more psychiatric morbidity (Table 2 ).

\subsection{PTSD caseness by SPAN-C}

Posttraumatic symptoms were common in our subjects. If an item on the SPAN-C was rated as 1 or higher, we would define that particular symptom as present. Rates for each symptom from the SPAN-C were as follows: startle, $65.4 \%$; physiological arousal, $66.3 \%$; anger, $55.8 \%$; and numbness, $50.2 \%$. The prevalence of PTSD caseness as defined by SPAN-C score of 5 or higher was 20.9\%. Factors significantly associated with PTSD caseness by SPAN-C were as follows: female sex $\left(\chi^{2}=78.7, d f=1, P<.000\right)$, divorced/widowed status $\left(\chi^{2}=13.7, d f=2, P=.001\right)$, low education level $\left(\chi^{2}=13.1, d f=2, P=.001\right)$, degree of house destruction $\left(\chi^{2}=5.6, d f=1, P=.018\right)$, and living in prefabricated house $\left(\chi^{2}=8.2, d f=1, P=.002\right)$ (Table 3$)$.

Results from the logistic regression with the above variables revealed that female sex $(P<.000)$, low education level $(P<.001)$, and age $(P<.001)$ were the best predictors for psychiatric morbidity. Currently living in prefabricated house $(P=.001)$ was also a significant predictor for psychiatric morbidity (Table 4).

Likewise, results from logistic regression with the above variables revealed that female sex $(P<.000)$ was the best predictor for PTSD caseness. Currently living in prefabricated house $(P=.008)$, low education level $(P=.009)$,

Table 3

Risk factors and PTSD caseness by SPAN-C

\begin{tabular}{lccc}
\hline & SPAN-C $\geq 5$ & SPAN-C <5 & $P$ \\
\hline Sex & & & \\
Male & $377(28.5 \%)$ & $2069(41.9 \%)$ & $<.000$ \\
Female & $947(61.5 \%)$ & $2873(58.1 \%)$ & \\
Age group (y) & & & \\
$\quad<40$ & $252(19.0 \%)$ & $972(19.7 \%)$ & .45 \\
$40-65$ & $692(52.3 \%)$ & $2487(50.3 \%)$ & \\
$>65$ & $380(28.7 \%)$ & $1483(30.0 \%)$ & \\
Marital status & & & \\
Single & $75(5.7 \%)$ & $359(7.3 \%)$ & .001 \\
Married & $983(74.2 \%)$ & $3781(76.5 \%)$ & \\
Divorced/widowed & $266(20.1 \%)$ & $802(16.2 \%)$ & \\
Education level & & & .001 \\
Primary school & $887(67.0 \%)$ & $3110(62.9 \%)$ & \\
High school & $359(27.1 \%)$ & $1405(28.4 \%)$ & \\
College and above & $78(5.9 \%)$ & $427(8.6 \%)$ & \\
Destruction of property & & & .004 \\
Completely destroyed & $748(56.5 \%)$ & $2611(52.8 \%)$ & \\
Partially destroyed & $576(43.5 \%)$ & $2331(47.2 \%)$ & \\
Current living environment & & & \\
Prefabricated house & $219(16.5 \%)$ & $665(13.4 \%)$ & \\
Not prefabricated house & $1105(83.5 \%)$ & $4277(86.6 \%)$ & \\
\hline Valus are presented as & & & \\
\hline
\end{tabular}

Values are presented as number (percentage). 
Table 4

Predictors of psychiatric morbidity and PTSD caseness by SPAN-C in multiple logistic regression model

\begin{tabular}{|c|c|c|c|c|c|c|}
\hline \multirow[t]{2}{*}{ Variable } & \multicolumn{3}{|c|}{ Psychiatric morbidity } & \multicolumn{3}{|c|}{ PTSD } \\
\hline & OR & $95 \% \mathrm{CI}$ & $P$ & OR & $95 \% \mathrm{CI}$ & $P$ \\
\hline Sex (female) & 1.40 & $1.25-1.56$ & $<.001$ & 1.73 & $1.51-1.99$ & $<.001$ \\
\hline $\operatorname{Age}^{a}$ & 0.83 & $0.76-0.91$ & $<.001$ & 0.93 & $0.83-1.03$ & .171 \\
\hline Marital status ${ }^{\mathrm{b}}$ & 1.07 & $0.99-1.14$ & .058 & 1.07 & $0.99-1.16$ & .087 \\
\hline Education $^{\mathrm{c}}$ & 0.82 & $0.75-0.90$ & $<.001$ & 0.86 & $0.76-0.96$ & .009 \\
\hline Destruction of property ${ }^{\mathrm{d}}$ & 1.03 & $0.93-1.14$ & .570 & 1.20 & $1.06-1.34$ & .039 \\
\hline Current living environment $\mathrm{e}^{\mathrm{e}}$ & 1.28 & $1.11-1.48$ & .001 & 1.26 & $1.06-1.49$ & .008 \\
\hline
\end{tabular}

OR indicates odds ratio; $\mathrm{CI}$, confidence interval.

${ }^{\text {a }}$ Coded as age $<40$ years $=0$, age 40-65 years $=1$, age $>65$ years $=2$.

${ }^{\mathrm{b}}$ Coded as single/married $=0$, divorced $/$ widowed $=1$.

c Coded as primary school $=0$, high school $=1$, college and above $=2$.

${ }^{\mathrm{d}}$ Coded as partially destroyed $=0$, completely destroyed $=1$.

e Coded as not prefabricated house $=0$, prefabricated house $=1$.

and complete destruction of property $(P=.039)$ were also significant predictors for PTSD caseness by SPAN-C (Table 4).

The marital status that significantly predicted psychiatric morbidity and PTSD caseness by SPAN-C in the bivariate analysis was not predictive in the multivariate analysis. Further analysis reveals that the marital status is significantly associated with sex and educational level.

There was a positive correlation between CHQ-12 score and SPAN score $(r=0.493, P<.001)$. Patients with PTSD caseness by SPAN-C also had a higher prevalence of psychiatric morbidity $\left(\chi^{2}=769.1, d f=1, P<.001\right)$.

\section{Discussion}

The findings of this 2-year follow-up of the Chi-Chi earthquake highlight the long-term impact of a major disaster on the survivors. This study found that the prevalence of psychiatric problems after a severe earthquake in Taiwan was comparable with the postdisaster rate reported elsewhere. The PTSD caseness by SPAN-C and the psychiatric morbidity were still prevalent 2 years after the earthquake.

In this study, we had no control population to compare the prevalence of psychiatric morbidity between affected and nonaffected population. Study using the same questionnaire (CHQ-12) to determine psychiatric morbidity showed a rate of $27 \%$ (using $2 / 3$ as cutoff) in the community [28]. Chen et al [10] also used CHQ-12 to assess 525 survivors in the first month after the Chi-Chi earthquake and revealed that the rate of psychiatric morbidity was $89.9 \%$. The rate of psychiatric morbidity, as defined by CHQ-12 greater than 4, was $24.5 \%$ among the Chi-Chi earthquake victims in primary care clinics 3 months after the disaster [22]. In comparison with the above data, the $39.8 \%$ prevalence rate of psychiatric morbidity obtained 2 years after the earthquake was high. This may be ascribed to different methodologies, the time elapsed between the onset of the disaster and data collection, the methods of sampling and case detection, and the diagnostic criteria, which make comparison of these retrospective findings difficult. Our study subjects lived near the epicenter of the Chi-Chi earthquake, and their dwellings were destroyed by it. Several studies reported that the more severe the psychiatric symptoms were, the closer were the victims to the epicenter [34].

The positive relationship between female sex and psychiatric morbidity after disaster was reported in several studies $[10,12,19,24]$. Our findings showed that the age and educational level of the victims were also risk factors of postdisaster psychiatric morbidity. The psychological stresses of reconstructing their lives and the lives of their families as well as finding new jobs have been found to be greater for the middle-aged subjects [35]. Armenian et al [36] also found that level of education was inversely related to the risk of PTSD. In addition, the current living status was significantly associated with the psychiatric morbidity. In our study, all of the study subjects' properties were completely or partially destroyed by the Chi-Chi earthquake. In the immediate aftermath of the earthquake, survivors were arranged to live in prefabricated houses. Those who had enough financial resources and manpower to repair or reconstruct their dwellings could move out of the prefabricated houses before this study period. Those subjects reported fewer symptoms and had lower prevalence of psychiatric morbidity.

The prevalence rate of PTSD caseness by SPAN-C in this study was $20.9 \%$. The prevalence rate of PTSD among the Chi-Chi earthquake victims after 4 to 10 months of the disaster was about $7.9 \%$ to $11.3 \%$ [19,20,22,24]. Like the findings of other studies, sex, educational level, and current living status were important factors that increased the likelihood of PTSD [12-14,19,24]. In addition, the degree of property destruction by the earthquake was significantly associated with the PTSD. To note, the study subjects were recruited from the epicenter of the Chi-Chi earthquake; and the earthquake partially or completely destroyed their dwellings. It is reasonably assumed that the extent of dwelling destruction could reflect the strength of trauma to some degree. Sharan et al [37] also found that the 
destruction of house and possessions was significantly associated with the psychiatric disorder. The destruction of house and possessions could act as life-threatening stressors, as losses, and as relocation stressors. Taiwanese culture is notable for its emphasis on the whole family as opposed to the individual. This cultural characteristic is illustrated by the finding that subjects with prominent house damage or living problems were at greater risk for psychiatric morbidity or PTSD [19]. Several studies reported that higher postearthquake support may buffer the psychological impacts of extensive earthquake damage [38,39], although contrary findings have also been reported [20]. For example, Lai et al [20] found that agency support and social support were not the important factors in the development of psychiatric morbidity and PTSD.

In this study, the psychiatric morbidity is strongly associated with a high level of posttraumatic stress. There are several possible explanations for this comorbidity [40]. There is a considerable symptom overlap between PTSD and several psychiatric disorders, most notably depression and other anxiety disorders. The high rates of comorbidity in PTSD might be simply an epiphenomenon of the diagnostic criteria used for all of these disorders [41,42]. Another hypothesis is that individuals with PTSD tend to report higher levels of symptoms when compared with individuals with other psychiatric disorders [43]. Finally, the high levels of comorbidity may be partially explained by the fact that the presence of certain psychiatric disorders (eg, major depression) is actually a risk factor for the development of PTSD and that they may have been present before the trauma [11,42].

The interpretation of these findings is limited by the methods used to screen the samples. These data are based on self-reported measures and may limit the strength of the conclusions. However, previous studies indicated that the CHQ [26] and SPAN-C [27] had satisfactory reliability and validity. The study subjects, whose houses were completely or partially destroyed by the earthquake, belonged to the high-risk group of psychiatric disorder. The findings cannot be generalized to all disaster victims. Nonetheless, compared with previous epidemiological studies, the response rate $(71 \%)$ was relatively high. This was accounted for by the close collaboration of various professions, particularly public nurses and local community officers. With their assistance, high response rates were able to be achieved. Moreover, because the survey also provided medical health assessment and laboratory tests, subjects were more likely to cooperate and provide reliable information. Demographically, the nonrespondents were disproportionately male and younger. They might have to work in the daytime or move to another county because of various reasons. This may lead to a bias in the interpretation of our results. Our study was a cross-sectional design and lacked the detailed evaluation of postdisaster factors that might influence the pattern of recovery (eg, postdisaster life events, ongoing disruptions, and consultations for psychological problems). However, the results of this study, which includes a large sample of earthquake survivors, can serve as a practical assessment for identifying those at risk of mental disorders.

\section{Acknowledgment}

The authors wish to thank Professor Andrew TA Cheng for the permission of the use of CHQ-12 questionnaire in this study.

\section{References}

[1] Rubonis AV, Bickman L. Psychological impairment in the wake of disaster: the disaster-psychopathology relationship. Psychol Bull 1991;109:384-99.

[2] Maj M, Starace F, Crepet P, Lobrace S, Veltro F, De Marco F, et al. Prevalence of psychiatric disorders among subjects exposed to a natural disaster. Acta Psychiatr Scand 1989;79:544-9.

[3] Goenjian AK, Steinberg AM, Najarian LM, Fairbanks LA, Tashjian M, Pynoos RS. Prospective study of posttraumatic stress, anxiety, and depressive reactions after earthquake and political violence. Am J Psychiatry 2000;157:911-6.

[4] Deering CG, Glover SG, Ready D, Eddleman HC, Alarcon RD. Unique patterns of comorbidity in posttraumatic stress disorder from different sources of trauma. Compr Psychiatry 1996;37:336-46.

[5] Bromet E, Dew MA. Review of psychiatric epidemiologic research on disasters. Epidemiol Rev 1995;17:113-9.

[6] Garrison CZ, Bryant ES, Addy CL, Spurrier PG, Freedy JR, Kilpatrick DG. Posttraumatic stress disorder in adolescents after Hurricane Andrew. J Am Acad Child Adolesc Psychiatry 1995; 34:1193-201.

[7] Goenjian A. A mental health relief programme in Armenia after the 1988 earthquake. Implementation and clinical observations. $\mathrm{Br} \mathrm{J}$ Psychiatry 1993;163:230-9.

[8] Armenian HK, Morikawa M, Melkonian AK, Hovanesian A, Akiskal $\mathrm{K}$, Akiskal HS. Risk factors for depression in the survivors of the 1988 earthquake in Armenia. J Urban Health 2002;79:373 - 82.

[9] Finnsdottir T, Elklit A. Posttraumatic sequelae in a community hit by an avalanche. J Trauma Stress 2002;15:479-85.

[10] Chen CC, Yeh TL, Yang YK, Chen SJ, Lee IH, Fu LS, et al. Psychiatric morbidity and post-traumatic symptoms among survivors in the early stage following the 1999 earthquake in Taiwan. Psychiatry Res 2001;105:13-22.

[11] Perkonigg A, Kessler RC, Storz S, Wittchen HU. Traumatic events and post-traumatic stress disorder in the community: prevalence, risk factors and comorbidity. Acta Psychiatr Scand 2000;101:46-59.

[12] Breslau N. The epidemiology of posttraumatic stress disorder: what is the extent of the problem? J Clin Psychiatry 2001;62(Suppl 17): $16-22$.

[13] Lewin TJ, Carr VJ, Webster RA. Recovery from post-earthquake psychological morbidity: who suffers and who recovers? Aust N Z J Psychiatry 1998;32:15-20.

[14] Kilic C, Ulusoy M. Psychological effects of the November 999 earthquake in Turkey: an epidemiological study. Acta Psychiatr Scand 2003;108:232-8.

[15] Ursano RJ, Kao TC, Fullerton CS. Posttraumatic stress disorder and meaning: structuring human chaos. J Nerv Ment Dis 1992;180:756-9.

[16] Bland SH, O’Leary ES, Farinaro E, Jossa F, Trevisan M. Long-term psychological effects of natural disasters. Psychosom Med 1996; 58:18-24.

[17] Carr VJ, Lewin TJ, Webster RA, Kenardy JA, Hazell PL, Carter GL. Psychosocial sequelae of the 1989 Newcastle earthquake: II. Exposure and morbidity profiles during the first 2 years post-disaster. Psychol Med 1997;27:167-78. 
[18] Kuo CJ, Tang HS, Tsay CJ, Lin SK, Hu WH, Chen CC. Prevalence of psychiatric disorders among bereaved survivors of a disastrous earthquake in Taiwan. Psychiatr Serv 2003;54: 249-51.

[19] Chou FH, Su TT, Chou P, Ou-Yang WC, Lu MK, Chien IC. Survey of psychiatric disorders in a Taiwanese village population six months after a major earthquake. J Formos Med Assoc 2005;104: $308-17$.

[20] Lai TJ, Chang CM, Connor KM, Lee LC, Davidson JR. Full and partial PTSD among earthquake survivors in rural Taiwan. J Psychiatr Res 2004;38:313-22.

[21] Hsu CC, Chong MY, Yang P, Yen CF. Posttraumatic stress disorder among adolescent earthquake victims in Taiwan. J Am Acad Child Adolesc Psychiatry 2002;41:875-81.

[22] Yang YK, Yeh TL, Chen CC, Lee CK, Lee IH, Lee LC, et al. Psychiatric morbidity and posttraumatic symptoms among earthquake victims in primary care clinics. Gen Hosp Psychiatry 2003; 25:253-61.

[23] Chang CM, Lee LC, Connor KM, Davidson JR, Jeffries K, Lai TJ. Posttraumatic distress and coping strategies among rescue workers after an earthquake. J Nerv Ment Dis 2003;191:391-8.

[24] Chang CM, Connor KM, Lai TJ, Lee LC, Davidson JR. Predictors of posttraumatic outcomes following the 1999 Taiwan earthquake. J Nerv Ment Dis 2005;193:40 - 6.

[25] Wu HC, Chou P, Chou FH, Su CY, Tsai KY, Ou-Yang WC, et al. Survey of quality of life and related risk factors for a Taiwanese village population 3 years post-earthquake. Aust N Z J Psychiatry 2006;40:355-61

[26] Cheng TA, Williams P. The design and development of a screening questionnaire (CHQ) for use in community studies of mental disorders in Taiwan. Psychol Med 1986;16:415-22.

[27] Chen CH, Shen WW, Tan HK, Chou JY, Lu ML. The validation study and application of stratum-specific likelihood ratios in the Chinese version of SPAN. Compr Psychiatry 2003;44:78-81.

[28] Cheng TA. A community study of minor psychiatric morbidity in Taiwan. Psychol Med 1988;18:953-68.

[29] Chong MY, Wilkinson G. Validation of 30- and 12-item versions of the Chinese Health Questionnaire (CHQ) in patients admitted for general health screening. Psychol Med 1989;19: 495-505.

[30] Goldberg DP, Hillier VF. A scaled version of the General Health Questionnaire. Psychol Med 1979;9:139-45.
[31] Davidson JR, Book SW, Colket JT, Tupler LA, Roth S, David D, et al. Assessment of a new self-rating scale for post-traumatic stress disorder. Psychol Med 1997;27:153-60.

[32] Chen CH, Lin SK, Tang HS, Shen WW, Lu ML. The Chinese version of the Davidson Trauma Scale: a practice test for validation. Psychiatry Clin Neurosci 2001;55:493-9.

[33] Meltzer-Brody S, Churchill E, Davidson JR. Derivation of the SPAN, a brief diagnostic screening test for post-traumatic stress disorder. Psychiatry Res 1999;88:63-70.

[34] Goenjian AK, Najarian LM, Pynoos RS, Steinberg AM, Manoukian G, Tavosian A, et al. Posttraumatic stress disorder in elderly and younger adults after the 1988 earthquake in Armenia. Am J Psychiatry 1994; 151:895-901.

[35] Kato H, Asukai N, Miyake Y, Minakawa K, Nishiyama A. Posttraumatic symptoms among younger and elderly evacuees in the early stages following the 1995 Hanshin-Awaji earthquake in Japan. Acta Psychiatr Scand 1996;93:477-81.

[36] Armenian HK, Morikawa M, Melkonian AK, Hovanesian AP, Haroutunian N, Saigh PA, et al. Loss as a determinant of PTSD in a cohort of adult survivors of the 1988 earthquake in Armenia: implications for policy. Acta Psychiatr Scand 2000;102:58 - 64 .

[37] Sharan P, Chaudhary G, Kavathekar SA, Saxena S. Preliminary report of psychiatric disorders in survivors of a severe earthquake. Am J Psychiatry 1996;153:556-8.

[38] Altindag A, Ozen S, Sir A. One-year follow-up study of posttraumatic stress disorder among earthquake survivors in Turkey. Compr Psychiatry 2005;46:328-33.

[39] Wang X, Gao L, Zhang H, Zhao C, Shen Y, Shinfuku N. Postearthquake quality of life and psychological well-being: longitudinal evaluation in a rural community sample in northern China. Psychiatry Clin Neurosci 2000;54:427-33

[40] McMillen C, North C, Mosley M, Smith E. Untangling the psychiatric comorbidity of posttraumatic stress disorder in a sample of flood survivors. Compr Psychiatry 2002;43:478-85.

[41] Keane TM, Kaloupek DG. Comorbid psychiatric disorders in PTSD. Implications for research. Ann N Y Acad Sci 1997;821:24-34.

[42] Brady KT, Killeen TK, Brewerton T, Lucerini S. Comorbidity of psychiatric disorders and posttraumatic stress disorder. J Clin Psychiatry 2000;61(Supp1 7):22-32.

[43] Hyer L, Fallon Jr JH, Harrison WR, Boudewyns PA. MMPI overreporting by Vietnam combat veterans. J Clin Psychol 1987; 43:79-83. 